\title{
RECUPERAÇÃO AMBIENTAL EM ASSENTAMENTOS RURAIS NO PONTAL DO PARANAPANEMA: UMA ANÁLISE DA TRAJETÓRIA DO PROGRAMA PONTAL VERDE ${ }^{1}$
}

\author{
José Luiz Fernandes Cerveira Filho \\ Doutorando no Programa de Pós Graduação em Ciências Sociais da \\ Universidade Federal de São Carlos-SP \\ E-mail: cerveira@bol.com.br
}

\section{Resumo}

A Fundação Itesp vem requisitando parte das terras públicas no Pontal do Paranapanema - SP, no intuito de possibilitar a criação de assentamentos rurais. Parte desses assentamentos encontram-se em intenso estado de devastação ambiental, com elevada taxa anual de perda de solo, o que tem refletido negativamente em seu desenvolvimento. Diante disso, em 1998, o órgão governamental formulou o "Programa Pontal Verde", objetivando promover a melhoria das condições ambientais na região do Pontal do Paranapanema, compatibilizando-as com o desenvolvimento socioeconômico das famílias assentadas. O objetivo desta pesquisa é fazer uma análise sobre a etapa inicial do "Programa Pontal Verde", avaliando as negociações ocorridas entre os vários atores sociais participantes. Para tanto, analisará as formas de ocupação ocorridas na região, observando a íntima relação existente entre o capital privado e a política governamental. Também serão discutidas, sob o enfoque analítico da teoria da estruturação, as dicotomias presentes nos discursos que visam promover a sustentabilidade relacionando-as às tomadas de decisões por parte dos agricultores. Por últi-

\footnotetext{
${ }^{1}$ Este artigo é uma versão resumida da Dissertação de Mestrado de mesmo título, apresentada ao Programa de Pós Graduação em Sociologia Política da Universidade Federal de Santa Catarina, em fevereiro de 2003.
} 
mo, por meio de um estudo de caso serão analisadas as transformações ocorridas no assentamento Santa Carmem, programa piloto do projeto, durante o período 1998-2000. Através de pesquisas qualitativas tentarse-a compreender as relações desencadeadas no âmbito das individualidades dos atores participantes, e como examinar estas se relacionam com o cenário macroestrutural, contribuindo para a construção e análise de novos paradigmas. Ao analisar-se o processo de implementação do Programa, buscar-se-á, especialmente, apreender como determinados conflitos / impasses operacionais acabaram convertidos em estratégias de resistências dos assentados ao programa estatal.

Palavas-chave: assentamentos rurais; Pontal do Paranapanema; devastação Ambiental.

região do Pontal do Paranapanema, localizada no interior paulista, é muito conhecida por seus conflitos fundiários. Ademais, nos últimos 10 anos, ela tem despertado o interesse de algumas organizações ambientalistas que têm procurado desenvolver alguns projetos de preservação do meio ambiente em conjunto com agricultores de comunidades assentadas. Além do interesse ambiental, esses projetos têm um outro ponto em comum: a não participação dos órgãos estatais. Do outro lado, o governo do Estado de São Paulo, distanciado de uma discussão que tem despertado cada vez mais o interesse popular, decidiu, ainda durante o primeiro governo de Mário Covas (1994-1998), criar um programa de recuperação ambiental através de uma rede própria.

"Um novo PONTAL está surgindo, cada vez mais VERDE". Essa frase foi escolhida para abrir o Pontal Verde: Programa de Recuperação Ambiental nos Assentamentos do Pontal do Paranapanema, por sintetizar o interesse do Instituto de Terras do Estado de São Paulo "José Gomes da Silva" (Itesp) em recuperar partes de uma região altamente devastada ambientalmente. Neste Programa, iniciado em 1998, foram reunidas todas as condições para a promoção do bem estar regional: interesse governamental, legitimação científica, comunidade organizada e 
rede de parceiros, governamentais ou não. Ele foi apresentado como um projeto agroecológico, vinculado aos paradigmas do desenvolvimento rural sustentável, que objetivava recompor determinadaa áreas florestais $\mathrm{e}$, concomitantemente, ampliar a renda do agricultor participante.

Contudo, não foi o que ocorreu. Algumas das metas programáticas propostas no "Pontal Verde" não foram totalmente alcançadas. Diante disto, questionamos: quais foram as dificuldades encontradas pelos promotores do "Programa Pontal Verde?" Quais foram as deficiências apresentadas pelo órgão fomentador desta política? Como um projeto apresentado pelo governo, com toda a infraestrutura disponível, é capaz de fracassar em alguns pontos-chaves? É isso que tentaremos responder neste artigo, que na primeira parte procurará caracterizar a etapa prévia à formulação do Pontal Verde, demonstrando como a ocupação desordenada da região tornou-se fator decisivo para a problemática ambiental.

O referencial teórico-metodológico que embasa este estudo concentra-se na segunda parte do artigo. A partir dos debates envolvendo o desenvolvimento rural sustentável, procuraremos caracterizar as dicotomias presentes nos discursos científicos que defendem a sustentabilidade agrícola e avaliar a trajetória do intercâmbio entre o conhecimento prático e técnico, mostrando como a racionalidade cultural orienta as estratégias de produção e de participação dos agricultores em determinados projetos. Também aqui analisaremos o papel da extensão rural no desenvolvimento da produção agrícola, observando as metodologias que intencionam promover o desenvolvimento rural com a participação do agricultor.

$\mathrm{Na}$ terceira parte analisaremos as relações entre os atores sociais envolvidos no "Programa Pontal Verde", procurando caracterizar a evolução das estratégias chamadas de participativas. Através de uma narrativa abordaremos os principais momentos da fase inicial do Programa, analisando as suas relações, suas parcerias e seu orçamento. Por último, apresentaremos um estudo de caso realizado nas duas primeiras áreas destinadas à recuperação ambiental, localizadas no Assentamento Santa Carmem, no município paulista de Mirante do Paranapanema, procurando dar sentido à ação dos envolvidos, assim como voz aos atores participantes. 
Por último, esclarecemos que a opção pela técnica do estudo de caso impôs-se por compreendermos que, enquanto modelo de levantamento de dados empíricos, ela permite-nos o acesso a informações privilegiadas e detalhadas sobre a realidade social, na qual os processos sociais se desenrolam concretamente, por entendermos que um estudo de caso se caracteriza pela busca da maior profundidade possível de informações e pela sua especificidade, que atua como contraponto à generalidade da teoria, o que nos permite levantar questões que podem passar desapercebidas em estudos muito abrangentes.

\section{Pontal do Paranapanema: dilemas sócioambientais}

O objetivo principal deste tópico é contribuir para a compreensão do processo de ocupação da região do Pontal do Paranapanema. Através de alguns trabalhos acadêmicos, e também de outras fontes, analisaremos como se deu a ampliação da fronteira agrícola paulista na região durante o século 20. Aqui, procuraremos apontar os interesses políticos e empresariais relativos à região, as quais, por vezes, constituíram-se em uma só unidade. Principalmente, focalizaremos a forma como esses fatores contribuíram para o atual quadro ambiental e social do Pontal e, por último, daremos as principais linhas de interesse e ação do "Programa Pontal Verde", formulado com a intenção de promover melhorias socioeconômicas e ambientais no Pontal.

A região do Pontal do Paranapanema é uma área do território paulista que está situada no extremo Sudoeste do estado, limitando-se ao sul com o Estado do Paraná e a oeste com o de Mato Grosso do Sul. Sua marcante característica física é dada pelo tipo de solo - arenitocaiuá - conhecido como terra mista, de cor avermelhada, fortemente arenoso e, sobretudo, de fertilidade efêmera. É importante ressaltar que a fragilidade desse solo tem-se constituído fator de alta preocupação. Podemos dizer que, junto à questão fundiária, este tem sido o foco das políticas publicas destinadas à região. O "Programa Pontal Verde " torna público esse interesse governamental ao propor a recuperação ambiental de algumas áreas degradadas através do controle das ero- 
sões e do estímulo à produtividade agrícola e à recuperação de outras espécies nativas.

A região do Pontal do Paranapanema é parte de uma antiga posse denominada Fazenda Pirapó-Santo Anastácio, de cerca de 700.000 hectares, que, os ocupantes, tendo tomado posse ilegalmente, tentaram legalizar declarando que ali tinham morada desde antes da publicação da Lei de Terras. Contudo, para a grande parte da população interessada nas terras, estas continuam devolutas, aparecendo centenas de pequenas posses na referida fazenda (LEITE, 1998). Nos anos 40s, o governador paulista Fernando da Costa criou o primeiro parque estadual no Pontal do Paranapanema. O decreto n ${ }^{\circ} 12.279$, de 29/10/1942 declarou reservada a gleba de terras consideradas devolutas nos perímetros que compreendem 37.156 hectares de área. Alguns dias depois, um novo decreto declara de utilidade pública um terreno com 13.343 hectares. Passados dezenove dias, o Diário Oficial paulista divulga novo decreto-lei criando outra área reservada, com 100.000 hectares. Globalmente, os três imóveis abrangeriam uma área de 297.340 hectares, dos quais apenas 4\% estaria fora da citada posse. Essa decisões tomadas pelo governante tinham como razão o fato de reinar na área a disputa de terras por causa da confusão de títulos e porque a frente pioneira na época ameaçava seriamente a integridade das últimas florestas de São Paulo.

Até 1940, a ocupação da Alta Sorocabana deu-se apenas ao longo dos trilhos da ferrovia. Somente a partir desta década é que as frentes começaram a se afastar da estrada de ferro em direção às terras mais novas do vale do rio Paranapanema. Os fatos que devem ser salientados são, sem dúvida, a grande procura de terras no período e a omissão do governo em proteger as suas terras. Ao passo que as terras ocupadas por particulares eram defendidas até mesmo à bala pelo seu ocupante, as do estado foram vítimas de aventureiros, grandes e pequenos, que passaram a disputar entre si pedaços de terras que não lhes pertenciam. Para tentar refrear esse ímpeto destrutivo, uma medida de caráter administrativo, tomada ainda no governo de Fernando Costa, passou a guarda das reservas ao Instituto Florestal (IF), conferindo-lhe responsabilidade pela integridade das reservas. Contudo, este mesmo governo não dotara o IF de meios necessários 
para exercer a guarda efetiva das reservas, e as invasões continuaram, ampliando-se a devastação.

Nos anos 50s, a imprensa da capital deflagrou uma grande campanha conservacionista, através, principalmente, dos jornais O Estado de São Paulo e a Folha de São Paulo, denunciando o tráfico de terras existente e as invasões das reservas florestais. A opinião pública paulistana mobilizou-se na conscientização da importância da preservação das matas e, para os governantes, a campanha mostrava que de nada valia criar reservas florestais por decretos, se estes não fossem acompanhados de um conjunto de outras medidas. Colocou-se então à mostra a realidade de um serviço florestal anacrônico e desprovido de meios para gerir de forma eficiente os espaços ecológicos reservados. O descaso do governo por suas reservas tornou-se notório (LEITE, 1998). Em virtude do caos em que se encontravam as divisas no Pontal do Paranapanema, com títulos irregulares perdendo-se por verdadeiros labirintos, as matas, assim como as fazendas, eram freqüentemente invadidas por posseiros ou mesmo por famílias que regularmente haviam adquirido terras.

No Pontal, durante o período militar (1964-1985) a presença da União se fez sentir através de alguns projetos hidrelétricos, como, por exemplo, das usinas de Rosana e o de Taquaruçu. No início das obras houve grande contratação de mão-de-obra, e, novamente, mais devastação das reservas florestais. Entretanto, posteriormente, a interrupção da construção da Usina Hidrelétrica de Rosana causou o fechamento de 2.500 postos de trabalho e a área alagada pela Usina Hidrelétrica de Taquaruçu desalojou algo em torno de 750 famílias de pequenos agricultores que não foram indenizados. Na análise de Antônio (1990; p.47):

Essas obras, com recursos públicos, além de promover a integração econômica na região, proporcionariam a elevação do padrão de vida da população e, sobretudo, criariam a expectativa de mais de trinta mil empregos. Entretanto, a década de 80 s, se caracterizou pela desaceleração das obras das usinas e pela conseqüente demissão de milhares de trabalhadores. Essa demissão em massa, somada às enchentes do rio Paranapanema, foram o estopim de uma situação crítica que já existia, renascendo assim o movimento social dos camponeses, e a partir daí toda a organização dos movimentos reivindicatórios por trabalho e terra. 
Para apreender a complexidade do atual quadro social regional focalizamos o surgimento, na primeira metade da década de 80 , dos movimentos sociais organizados na região. Através de diversas lutas, alguns atores sociais foram construindo condições políticas para a troca de experiências, fortemente amparados pela Comissão Pastoral da Terra (CPT) e pelas Comunidades Eclesiais de Base (CEB). Além das lutas de resistência dos pequenos agricultores e bóias-frias, emergiu também, no Pontal, um novo personagem na luta pela terra: o trabalhador expropriado e expulso de sua terra, o "sem-terra". Em 1983 aconteceu a primeira grande ocupação, por 350 famílias, na fazenda Tucano, de propriedade da construtora Camargo Correia. Segundo o cadastramento feito pela Divisão Regional de Promoção Social, 46,5\% das invasões eram trabalhadores desempregados das obras hidrelétricas, $37,5 \%$ eram bóias-frias e $16 \%$ eram atingidos pelas barragens (ANTÔNIO, 1990, p.50).

Em março de 1984, o ex-governador Franco Montoro assinou os primeiros decretos de desapropriação, causa da reação dos fazendeiros da região que, em resposta, criaram a União Democrática Ruralista (UDR) para a defesa institucional de seus interesses. Entretanto, os movimentos sociais não se intimidaram e passaram a promover organizadamente uma série de novas ocupações de terras. Já em 1985 foram promulgadas duas leis relevantes para a política agrária estadual: a Lei n ${ }^{\circ} 4.925 / 85$, que dispõe sobre a alienação de terras públicas estaduais a agricultores que as ocupariam e explorariam, e a Lei $n^{\circ}$ $4.957 / 85$, que dispõe sobre as políticas de aproveitamento e valorização dos recursos fundiários do Estado, prevendo a destinação de terras públicas estaduais para a implantação de assentamentos de trabalhadores rurais. Possibilitou-se assim a implantação de uma série de assentamentos rurais na região do Pontal do Paranapanema. Ainda assim, o Pontal entraria definitivamente na agenda governamental somente a partir dos anos 90 s, principalmente pelos violentos conflitos agrários ocorridos no município de Mirante do Paranapanema. Neste município, entre 1990 e 1995, uma área com cerca de 13.000 hectares foi ocupada por 1.300 famílias.

Um importante indicador da problemática territorial regional é o da concentração da estrutura fundiária deste município. Os números 
apresentados pelos Censos Agropecuários do IBGE, entre 1970 e 1985, refletem sobremaneira 0 acúmulo de terras ocorrido durante o militarismo. Em 1970, 1.727 estabelecimentos agrícolas $(91,12 \%)$, de tamanho inferior a 100 hectares, ocupavam uma área de 29.148 hectares $(26,48 \%)$, e, do outro lado, apenas 19 estabelecimentos (1\%), com mais de 1.000 hectares, utilizavam-se de 40.385 hectares do município (36,60\%). Os números relativos ao ano de 1985 apontam para um aumento na concentração: nesse ano, os estabelecimentos menores que 100 hectares eram 882 (81,82\%), ocupando uma área de 20.170 hectares (16,80\%), ao passo que os com mais de 1.000 hectares, em número de $24(2,22 \%)$, ocupavam 51.020 hectares $(42,50 \%)$. Ao analisar estes dados, podemos concluir que a forma irregular de ocupação do município, ocorrida desde o início do processo, foi o principal fator responsável pela concentração da estrutura fundiária em seu território. Podemos concluir, também, que o período militar teve como marca fundamental o agravamento desse quadro. Todavia, os números do Censo Agropecuário de 1995/96 demonstram significativa distensão deste quadro. Como resultado pragmático dos vários conflitos sociais, bem como das diversas negociações burocráticas, espraiou-se por este município, assim como por toda região, uma série de assentamentos, mediados, principalmente, pelo Movimento dos Trabalhadores Rurais Sem Terra (MST) e pelo Instituto Nacional de Colonização e Reforma Agrária (INCRA).

A partir de 1998, o Itesp tem tentado homogeneizar seu discurso, promovendo programas de capacitação para seus técnicos, agrônomos, veterinários e zootecnistas, entre outros profissionais, e também para alguns agricultores assentados. Para a Diretoria Executiva, "esta é uma política voltada para a melhoria da qualidade de vida do agricultor assentado, através da internalização de valores considerados fundamentais para se alcançar o tão desejado desenvolvimento sustentável" (FUNDAÇÃO INSTITUTO DE TERRAS DE SÃO PAULO "JOSÉ GOMES DA SILVA, 1998, p.viii). Desde esta perspectiva, "a reforma agrária não é apenas um campo privilegiado para o desenvolvimento de políticas de cunho político, social e econômico mas é também ambiental". Esta visão do órgão, assumida pelos quadros diretivos como conservacionista, está baseada em experiências governamentais na condução dos primeiros assentamentos rurais, principalmente aque- 
les onde a ausência de uma metodologia pautada na maior participação do agricultor foi decisiva para o seu insucesso. Ultimamente, "todas as ações do órgão incluem uma preocupação com a participação do assentado, principalmente no trato da coisa ambiental, visando o respeito à legislação específica de modo a proporcionar um desenvolvimento sustentável às comunidades assentadas" (FUNDAÇÃO INSTITUTO DE TERRAS DE SÃO PAULO “JOSÉ GOMES DA SILVA, 1998, p.ix), sendo esta atenção mais significativa nos assentamentos localizados em áreas de proteção ambiental².

Esta preocupação levou o Itesp a "sair da informalidade" na questão ambiental. Em 1998 formou-se o Grupo de Gestão Ambiental (GGA) que passou a embasar os extensionistas do órgão nestas questões. Este grupo conseguiu, através de alguns cursos, disseminar uma "onda agroecológica" no Itesp. Ele está ligado à Gerência de InfraEstrutura e Meio Ambiente, que faz parte da Diretoria Adjunta de Políticas de Desenvolvimento que, por sua vez, está abaixo da Diretoria Executiva. Na alçada do GGA estão inseridos alguns programas ambientais, tais como educação ambiental, incentivo ao reflorestamento comercial, uso sustentável das florestas, conservação de solo e recuperação ambiental. A partir da formatação de "alguns escritos", este grupo aglutinou determinados programas do Itesp que tinham interfaces com a questão ambiental, posteriormente traduzidos no "Programa Pontal Verde", que foi elaborado em conjunto com o já extinto Grupo Florestas Sociais (GFS) - núcleo de pesquisas agroecológicas vinculado à Escola Superior de Agricultura Luiz de Queiroz da Universidade de São Paulo (Esalq / USP). No caso do GGA, através da análise da trajetória profissional de seus funcionários, observamos que alguns de seus membros são ex-alunos da escola, o que, em certa medida, facilitou o trâmite burocrático do programa.

As áreas a serem recuperadas, dentro da proposta do Programa, podem ser agrupadas da seguinte maneira: a) áreas de Preservação Permanente (APP), que não permitem retorno econômico; b) áreas de voçorocas, que se quer recuperar mecanicamente; e c) áreas de Reserva de Floresta Legal (RFL), que permitem a exploração econômica. As estratégias de implantação dividem-se entre as que têm um caráter direto e as que têm caráter indireto. A primeira forma não previa a 
participação do agricultor assentado no desenrolar dos projetos, que são os casos das voçorocas e das APP. Já a indireta - que é a que nos interessa - pretendia um modelo metodológico que buscasse a participação do agricultor, ressaltando as possibilidades de retornos financeiros a curto, médio e longo prazo, que são os casos das RFL. Para a consecução de seus objetivos, o GGA pretendia ainda fomentar convênios com a Secretaria do Meio Ambiente, com a Secretaria de Educação, com as organizações que atuam na região e com as universidades regionais, entre outros.

\section{Sustentabilidade e participação}

Nas últimas duas décadas, tem proliferado, dentro da comunidade científica um certo consenso sobre a degradação ambiental ocasionada pelas formas de ocupação do solo. Com a equação meio ambiente / agricultura que tem sido objeto de algumas inquietações metodológicas, visa-se orientar um grande número de pesquisadores na análise dos projetos de desenvolvimento rural focados na sustentabilidade agrícola. Nos últimos 50 anos a noção de desenvolvimento introduziu-se como uma idéia de grande interesse, com o objetivo de orientar diversos programas governamentais. Nessa esfera, um primeiro momento pode ser identificado com o fim da Segunda Guerra, que se estendeu-se até o final do decênio de 1970. Nesse período, a idéia de desenvolvimento estimulou iniciativas em diversos setores sociais. Dessa forma, o que conhecemos por desenvolvimento rural foi um dos grandes motores das políticas governamentais na época. Efetivamente, entre 1950 e 1985, foi o responsável por um grande aumento na produtividade agrícola mundial. Um segundo momento situase nos questionamentos sobre este modelo de desenvolvimento. A partir de então os debates sobre desenvolvimento rural modificaram-se significativamente, caracterizando-se mais por uma percepção acerca

\footnotetext{
${ }^{2}$ Torna-se importante esclarecer ao leitor que grande parte da análise a seguir apóia-se em nosso trabalho de campo. As citações que não trouxerem a referência explícita são trechos das entrevistas realizadas com os atores responsáveis pela rede.
} 
da aparente impossibilidade do desenvolvimento exclusivamente focalizado no crescimento econômico.

A expressão "desenvolvimento rural sustentável" passou a ser difundida em meados dos anos de 1980 a partir da crescente referência à expressão mais geral "desenvolvimento sustentável". Desde lá, muitos autores procuraram agregar um sentido politicamente mais conseqüente ao termo, incorporando à sua agenda, entre outros pontos, as noções de eqüidade social - alguma suposta relação entre o arranjo social das famílias rurais mais pobres com o desenvolvimento rural sustentável - e sustentabilidade agrícola. Guivant (1997) apresenta um ponto que deve ser observado: a dimensão social da questão. A sustentabilidade não só diz respeito às conexões entre sociedade e agricultura, como também remete a problemas e contradições sociais mais gerais que igualmente devem ser pensados a partir de um programa mais global de desenvolvimento sustentável. Nesse sentido, o componente "sustentável" da expressão estaria referindo-se ao plano ambiental, indicando a necessidade de as estratégias de desenvolvimento rural incorporarem uma apropriada compreensão das dimensões ambientais. A tendência, desta forma, é que a expressão desenvolvimento rural sustentável esteja acrescida, cada vez mais, do componente ambiental derivado da noção de sustentabilidade agrícola.

A partir deste ponto começamos a nos indagar que tipo de orientações norteiam os agricultores na opção por um determinado tipo de prática agrícola. Reintjes et al. (2000) assinalam que, para uma possível adesão consciente do agricultor a uma agricultura de menor impacto ambiental, existiria a necessidade do mesmo possuir capacitação técnica, bem como dispor de capital. Entretanto, Lockeretz, (1989 apud GUIVANT, 1997) refuta a tese da capacitação técnica como um empecilho à implantação deste tipo de agricultura, argumentando que as dificuldades requeridas por ambos os modelos agrícolas são equivalentes, principalmente se considerarmos os agricultores como capazes de conhecer e adaptar seu conhecimento a diferentes condições. Como, então, entender as racionalidades que orientam os produtores familiares na condução de sua produção agrícola? Podemos aqui recorrer à teoria formulada por Giddens (1989) para nos aproximarmos de um entendimento que, por sua vez, nos permita entender as lógicas envolvidas neste processo. 
Através da sua teoria da estruturação, é possível evitar uma análise objetivista do processo de adoção de uma determinada tecnologia.

Guivant (1992), adaptando Giddens, considera que os agricultores não podem ser considerados pela antinomia racionalidade / irracionalidade. Suas decisões devem ser vistas como resultado de adaptações em razão da observação e da experimentação e, portanto, de diversas racionalidades envolvidas nessa tomada de decisão. Para Guivant (1992, p.88), "pequenos agricultores tomam suas decisões dentro de múltiplos objetivos, expectativas, pressões e outros fatores que podem ser agrupados em três grandes categorias, segundo o meio no qual os agricultores conduzem a produção: 1) os recursos físicos; 2) os fenômenos microsociais (família, comunidade); e 3 ) os fenômenos macrosociais (instituições nacionais, mercado, regulações governamentais)".

Visto desta forma, o agricultor deve criar arranjos adaptativos a estes três planos como meio efetivo para orientar as suas atividades produtivas. Assim, por exemplo, a decisão de participar ou não de um programa de desenvolvimento rural sustentável, ou mesmo aderir a uma nova tecnologia, não pode ser entendida como se tratasse de aspecto unicamente de racionalidade econômica. "A racionalidade aparece limitada pelas tensões diárias do mundo social e pelas diversos objetivos humanos" (GUIVANT, 1992, p. 89). É a racionalidade cultural que orienta os atores sociais através dos complexos processos de escolha. Em tais processos estão envolvidas cognições construídas e compartilhadas socialmente que dão sentido aos atores sociais no entendimento sobre a eficiência de uma nova tecnologia, um novo insumo ou um novo programa governamental. Nem sempre os critérios de sua implementação por parte dos agricultores corresponderão às recomendações dos técnicos extensionistas. As relações entre o que é difundido e as razões pelas quais os agricultores adotam os critérios que orientam sua implementação não são necessariamente lineares. As vantagens ou desvantagens de participar de um determinado projeto, segundo critérios técno-científicos, não são necessariamente óbvias para a racionalidade cultural dos agricultores.

Para uma melhor compreensão das possibilidades de tal processo é importante ampliar a análise das bases sociais da produção, 
incluindo as formas pelas quais os agricultores, enquanto grupo social, estruturam cognitivamente suas práticas agrícolas. E dessa forma que deve ser analisado o significado que eles dão ao que fazem. Temos que considerar os agricultores a partir de um referencial teórico que enfatiza o pluralismo causal - no sentido weberiano que influencia o processo decisório. A racionalidade cultural, combinada aos fatores estruturais, pode fundamentar-se teoricamente a partir de uma concepção que considera que o ator social nem plenamente ativo nem plenamente passivo em face das regulamentações normativas ou diretrizes e estratégias de um determinado projeto. Tal racionalidade parte de um entendimento diferente do que é o ator social, que possibilita compreender como, por exemplo, a implantação de um projeto se realiza dentro de critérios de legitimação construídos socialmente pelos atores sociais envolvidos no processo de adoção, sem que acatem rigorosamente as recomendações sugeridas tecnicamente. Existe um espaço, embora limitado, de produção de conhecimentos, dentro da reprodução de um padrão de conhecimentos dominante.

Esta abordagem teórica oferece ferramentas conceituais para captar a complexidade dos processos de participação de produtores rurais em programas destinados à melhoria das condições socioeconômicas, pois ela parte da idéia de que toda produção social pode ser também pensada como reprodução das estruturas sociais existentes. A sociedade não pode ser considerada como um poder de coação completo sobre os atores sociais, nem estes podem ser vistos como plenamente livres diante das determinantes sociais. As relações sociais estruturam-se sem determinismos e sem dualismos, segundo o que é captado no conceito de "dualidade das estruturas" de Giddens (1989), significando justamente que as estruturas sociais e, dentro delas, as relações sociais, são constituídas pela agência humana; ao mesmo tempo aquelas são o meio desta constituição. Portanto, toda ação humana é duplamente estruturada, na medida que é tanto estruturada como estruturante: atuando é que ela cria as condições para continuar atuando. A teoria da estruturação rejeita tanto a visão voluntarista de que os homens fazem a sociedade como a visão determinista de que a sociedade faz os homens. 
Dessa forma, a teoria da estruturação é uma interessante solução para fugir do dilema existente nas Ciências Sociais entre as micro análises e macro análises. Ela rejeita estes conceitos porque esses levam implícitas a idéia de que o pesquisador tem que optar por uma visão ou por outra. Os que se situam dentro da análise microssociológica defendem que nos pequenos eventos do cotidiano está a essência da realidade social, enquanto os que se definem como estudiosos da macrossociológia tendem a ver os estudos sobre o cotidiano como triviais e irrelevantes. Por um lado, o pesquisador que focaliza o aspecto microssocial, concentra-se no agente livre, enquanto o que focaliza o macrossocial, analisa as características estruturais que limitam a livre ação dos atores sociais. A ação social tem dois componentes que se devem ter em consideração para evitar tal dicotomia: 1) o referente às possibilidades sempre existentes de que $o$ ator social atue de uma forma diferente da habitual; 2) o referente aos conhecimentos que os atores têm das regras, normas e valores sociais, não sempre de forma consciente, e que lhes dão possibilidade de agir com comunicabilidade, estabelecendo conversações e negociações. Os atores sociais, embora possam não ser conscientes disto, têm uma capacidade transformadora de "fazer uma diferença" (termo utilizado por GUIVANT, 1992) na produção de suas práticas e assim transformar os padrões de ações sociais dominantes. Para a teoria da estruturação, todos os seres humanos são agentes cognoscitivos. Isto significa que os atores sociais possuem diversos tipos de conhecimentos sobre as condições e as conseqüências de suas ações cotidianas.

A cognoscitividade no plano da consciência discursiva expressa-se como critérios de credibilidade ou de legitimação usados pelos agentes para justificar o que fazem; isto é, sua prática e o conhecimento prático que a possibilita. Estes critérios representam um certo consenso sobre significados dados à realidade social e natural pelos membros de uma comunidade. As análises sobre os valores implícitos nas ações sociais devem caminhar entre as possíveis derivações da racionalidade que os atores dão ou imaginam dar as suas opções, já que os valores não são sempre conscientes e as decisões não são sempre deliberadas (GUIVANT, 1992). Os critérios de 
legitimação são algo mais que meros legitimadores de estruturas sociais. Eles podem ser considerados como variantes predominantes e guias em todo o sistema econômico, estando presentes, uma vez codificados pelas culturas, como parâmetros efetivos de opiniões, opções, decisões, percepções e até possibilidades de mudança e transformação social, cultural, política, econômica e, é o que aqui nos interessa, ambiental.

No plano da cultura dá-se a integração de tais critérios de legitimação, sendo eles parte do mapa cognitivo mais amplo a partir do qual os agentes sociais interpretam a realidade social e natural, mantendo comunicabilidade entre os membros do mesmo grupo social. Este mapa cognitivo refere-se tanto à realidade como ela é quanto a modelos de como a realidade deve ser (GEERTZ, 1984 apud GUTVANT, 1992), orientando os indivíduos no que podem esperar da realidade social e natural, mas sem dizer necessariamente como atuar. Tal mapa cognitivo está configurado a partir de determinadas crenças, atitudes, normas, valores, percepções, motivações, significados e um corpo de conhecimentos práticos. É segundo o conhecimento prático, construído através de uma lógica prática, que guia grande parte de nossas condutas cotidianas, através de princípios de classificação, de hierarquização, de divisão, que são princípios de julgamento, de análise, de percepção, não explicitados nas práticas.

Recentemente, pesquisas nos campos da sociologia do desenvolvimento promoveram significativas contribuições para a compreensão dos processos de conhecimento. Algumas propõem uma análise centrada nos atores, enfatizando que o conhecimento é interpretado como constituído pela forma como as pessoas codificam suas experiências e lhes atribuem significados. Ensinam com Long e Villareal (1994, p.64): “...os processos de desenvolvimento são inevitavelmente complexos, permeados por descontinuidades de interesses, valores e distribuição de poder, envolvendo negociações, acomodações e conflitos". Atualmente há uma corrente acadêmica que procura a integração dessas análises, por um lado, desmistificando os conhecimentos dentro da sociologia do rural e, por outro, caracterizando os conhecimentos envolvidos nestes processos como híbridos, buscando combinar elementos naturais, sociais e técnicos. Na análise de Guivant (1997, p.441): 
[...] o conhecimento local, enquanto híbrido, envolve uma heterogeneidade de manifestações que não o reduzem exclusivamente ao conhecimento tradicional. Por sua vez o conhecimento sustentável, também enquanto híbrido, envolve diferentes possíveis combinações entre o conhecimento local e o científico.

Dentro desta perspectiva, a dinâmica social envolvida nos processos de desenvolvimento rural é entendida como um processo de conflitos e negociações em que os agricultores, junto a empresários, políticos e educadores, entre outros atores, são, ou tornam-se, partes ativas no desenvolvimentos dos programas sociais. Esse enfoque, centrado nos indivíduos, define-se pela maneira como esses atores sociais implementam, à luz de suas respectivas referências culturais, as suas próprias estratégias, e como estas articulam-se com os processos sociais de maior escala, alterando sensivelmente as metas de determinadas políticas formuladas para o setor. Sem desconsiderarem as pressões macroestruturais, tornase imperativo integrar mais os agricultores nas análises, não como obviedade mas como produto de uma construção teórica.

À luz dos complexos processos que envolvem as tomadas de decisões e as aquisições e transmissões de conhecimentos, a extensão rural assume uma posição de destaque no que diz respeito às mudanças no comportamento dos agricultores. Na disseminação das técnicas contida no ideário da Revolução Verde,

[...] a extensão rural passou a ter como papel central o de educar as populações rurais de forma a possibilitar a transformação dos conhecimentos tradicionais, caracterizados como ineficientes e irracionais e, conseqüentemente, como obstáculos para a adoção de pacotes tecnológicos (GUIVANT, 1997, p.412).

A partir desta análise, observamos que o modelo convencional de abordagem da extensão rural para a agricultura contribuiu sensivelmente para a transformação das práticas agrícolas tradicionais. A rigor, as primeiras experiências de participação de agricultores em projetos governamentais embasavam-se na relação entre causa e efeito.

A procura por formas de diálogo para minimizar a distância entre o planejamento técnico e a execução social acaba colocando em evidên- 
cia a problemática das abordagens participativas. Este conceito invoca a relação entre as partes envolvidas e se contrapõe à concepção dos agricultores como "receptáculos passivos" de intervenções bem-intencionadas e tecnicamente perfeitas. Trata-se de uma nova fase, de um desafio. A literatura disponível já apresenta experiências bem sucedidas de intervenção social para a promoção da sustentabilidade agrícola, realizadas mediante a integração entre cientistas de diferentes áreas, técnicos voltados para a difusão das boas experiências, e agricultores, em uma proposta que tem sido denominada de Desenvolvimento Participativo de Tecnologia (DPT) (REIJNTES et al., 2000). A sua principal proposta é a de estimular um desenvolvimento graças a qual os próprios agricultores definam suas prioridades e necessidades, possibilitando uma ligação complementar entre as potencialidades das ciências da agricultura e as expectativas e conhecimentos dos agricultores participantes. A opção metodológica pela abordagem participativa exige também uma lógica diferenciada no envolvimento dos atores sociais em um novo mundo de conflitos e negociações, tendo que se confrontar com rejeições e modificações significativas da idéia original. Contudo, sem a predisposição para negociar, a participação torna-se uma fachada retórica, encobrindo interesses para legitimação de ações predefinidas.

\section{A construção do Pontal Verde}

Nesta última parte do artigo analisaremos, primeiramente, os pressupostos que embasam o "Programa Pontal Verde", procurando focar a sua ênfase na questão ambiental. A partir daí analisaremos o início da sua implantação participativa, observando suas dificuldades burocráticas enquanto tentativa de legitimar-se como política pública que visava a melhoria da qualidade de vida das comunidades assentadas. Por último, analisaremos as relações sociais desencadeadas a partir deste início, apresentando um estudo de caso realizado no Assentamento Santa Carmem, destacando a performance de duas áreas destinadas à recuperação ambiental.

O "Programa Pontal Verde" foi instituído em maio de 1998 pelo Itesp, conseguindo organizar a primeira reunião apenas em novembro 
desse ano. Em contraposição à retórica oficial do próprio órgão, as dificuldades burocráticas e a falta de maior apoio institucional aparecem claramente colocadas pelo GGA quando faz referência ao início operacional. A partir de um encontro realizado no dia 6 de novembro de 1998, na sede do Parque Estadual do Morro do Diabo, localizado no município paulista de Teodoro Sampaio, montou-se o atual formato do "Programa Pontal Verde". Nesta reunião foram delineados os objetivos e as metas: criou-se um grupo gestor, e os representantes das coordenadorias regionais do Itesp ficaram com a tarefa de identificar as áreas que poderiam ser consideradas piloto.

A estratégia de implantação previa uma série de atividades nas áreas-piloto. O GGA, desde o seu ponto de vista, procurou escolher como área-piloto para o Programa um assentamento que reunisse algumas características consideradas importantes, tais como área típica aos seus aspectos físicos, bióticos e antrópicos, boa localização em relação a outros assentamentos, fácil acesso, área significativa de RFL a ser recuperada, comunidade organizada e pouco tempo de implantação. Dessa maneira, a área escolhida para piloto do "Programa Pontal Verde " foi o Assentamento Santa Carmem, localizado no município de Mirante do Paranapanema. Nesta área encontravam-se 37 lotes, de 16 a 22 hectares cada um, que ocupavam juntos 765,78 hectares, e uma RFL de 270, 57 hectares totalmente desprovida de vegetação arbórea.

Julgamos que, neste ponto, os idealizadores do "Programa Pontal Verde " não fizeram a correta leitura a respeito de uma das principais características deste Assentamento: a comunidade organizada. O Santa Carmem é famoso na região por sua desarticulação. Historicamente, seus ocupantes fizeram parte das lutas promovidas pelo MST no município no início dos anos de 1990. Através das ocupações e, posteriormente, das legalizações promovidas pelo Incra, obtiveram o acesso à terra em 1995. Porém, desde o início, constatou-se uma série de desentendimentos entre os agricultores assentados. Ressalta-se também que boa parte deles recusaram-se a permanecer sob a tutela do MST, e esse desejo culminou na criação da Associação dos Agricultores do Assentamento Santa Carmem. Essa Associação durou tempo suficiente para marcar o Santa Carmem como um dos assentamentos que repeliram o MST após a conquista da terra. 
Também a educação e a capacitação ambientais apareceram como demandas do Programa. Nesse sentido, no início de 1999, o GGA tentou montar parceria com a Secretaria de Educação. "Foram feitos vários contatos" para a construção do Projeto de Educação Ambiental, "que previa a execução de ações de capacitação, sensibilização e informação, articuladas entre si de maneira a alcançar objetivos comuns" (FUNDAÇÃO INSTITUTO DE TERRAS DE SÃO PAULO "JOSÉ GOMES DA SILVA, 1998, p.42). O objetivo deste subprojeto foi inicialmente identificar a percepção dos professores da rede estadual de ensino acerca do meio ambiente, dos problemas ambientais e do modo de lidar com a questão. Outra parceria que procuramos observar foi a pretendida pelo Itesp e Secretaria de Meio Ambiente, que não avançou devido "às dificuldades burocráticas, que foram (e são) muito grandes para um trabalho contínuo entre os órgãos".

As pretendidas parcerias junto à Cooperativa de Comercialização e Prestação de Serviços dos Assentados da Reforma Agrária do Pontal do Paranapanema (Cocamp) e ao Instituto de Pesquisas Ecológicas (Ipe) também não vingaram. Para a Cocamp o governo paulista tem sido omisso em relação à região. Sobre a reunião ocorrida no Morro do Diabo, apontada pelo GGA como contraponto ao pacote tecnológico do Pontal Verde, "foi só para apresentar o Programa, não foi para perguntar o que a gente achava" relatou um militante. Quanto ao Ipe, os seus agentes perceberam dificuldades em trabalhar com os cronogramas apresentados pelo Itesp. Segundo seu porta-voz, "não podemos ficar perdendo tempo porque não saiu o dinheiro [...] qualquer mudança ou atraso no repasse de verbas pode acarretar em sérios problemas". Segundo o coordenador do GGA, "quando montamos o Pontal Verde, tivemos uma discussão com o pessoal do Ipe e da Cocamp. Sentimos algumas dificuldades de trabalhar juntos, principalmente com o Ipe [...] Eles tem uma forma de trabalhar diferente da nossa". As perdas destas parcerias foram muito significativas para o GGA, notadamente aquela pretendida junto ao Ipe. Esse almejado parceiro era considerado muito importante na divulgação da problemática ambiental. Quanto à Cocamp, o lamento pela não-concretização da parceria diz respeito à capacidade que teria esta instituição para organizar os agricultores. 
Do ponto de vista orçamentário, o "Programa Pontal Verde" contou inicialmente com verbas do próprio Itesp. Também contou com trabalhos executados através de um contrato de prestação de serviços que o Itesp mantém com a Companhia de Desenvolvimento Agrícola do Estado de São Paulo (Codasp), cujas verbas são repassadas diretamente pela Secretaria da Fazenda de São Paulo. De acordo com nossa análise, se por um lado o Itesp procura recriar-se em fundação visando uma maior agilidade aos seus trabalhos, por outro, os mecanismos de repasse de verbas públicas para a compra de determinados produtos continuam assentados em parâmetros antigos. Prevendo essas dificuldades orçamentárias, os formuladores do "Programa Pontal Verde" idealizaram parcerias entre os agricultores no manejo das áreas a serem recuperadas.

Quando foram definidas as duas áreas iniciais, quatro agricultores se interessaram e, rapidamente, os técnicos do GGA conheceram as dificuldades de trabalhar coletivamente: os agricultores não aceitaram trabalhar em parceria. Neste momento, o GGA insistiu em suas metas e procurou convencer os agricultores que esta era a única maneira de eles poderem participar. Quando indagado sobre os critérios utilizados para a seleção dos primeiros agricultores participantes, o Coordenador desse grupo foi político: "A gente chega, conversa com as famílias na primeira reunião. Às vezes é uma área que está no cantinho [...] que tem quatro famílias, quatro lotes em volta [...] então a gente não chama a comunidade inteira, chama só aqueles quatro lotes". E depois, em um segundo momento, tornou-se incisivo: "Na verdade, estas áreas são do estado, mas são áreas que a comunidade interage com ela".

Desta maneira formaram-se as primeiras parcerias: para o que chamaremos de área 1 foi firmada parceria entre os agricultores dos lotes 08 e 10, e, para a área 2, parceria entre os agricultores dos lotes 28 e 29. Observamos, primeiramente, que as parcerias não foram firmadas espontaneamente entre os agricultores, mas sim por imposição do GGA. Quanto a esta tentativa de organizar o coletivo sem um conhecimento prévio das estratégias dos agricultores, e também quanto às mudanças ocorridas nesta fase do "Programa Pontal Verde", o GGA responde que "mudou bastante". Esta pesquisa observou, ainda que, existem algumas relações internas no Itesp, como as dadas entre os técnicos 
do GGA e os agrônomos extensionistas. Essas relações situam-se em um patamar de maior conflituosidade. De um lado os engenheiros florestais e agrícolas acusam os agrônomos de serem simpáticos ao modelo convencional de agricultura. Do outro, estão os agrônomos que entendem que os técnicos do GGA não estão preocupados com o mercado agrícola, e tampouco com os ganhos dos agricultores.

Realizadas as alterações iniciais, o "Programa Pontal Verde" definitivamente saiu do papel e foi para a terra. A partir deste ponto do nosso trabalho, procuraremos analisar o seu início pela análise das duas áreas que foram dispostas para a recuperação.

\section{Área 1}

A área 1, com dois hectares, foi inicialmente compartilhada pelos agricultores dos lotes $n^{\circ} 08$ e 10 . A estratégia desses agricultores, depois de algumas discussões, levou-os a planejarem o plantio das mudas em consórcio com a lavoura de feijão. Porém, eles conseguiram plantar as mudas apenas no final de março e, reconsiderando suas estratégias, optaram por plantar mandioca. Entretanto, no desenrolar daquele semestre, durante a condução das atividades relacionadas à produção, os agricultores se desentenderam quanto à divisão dessas atividades. $\mathrm{O}$ agricultor do lote 08 , que contava com a ajuda de um filho na realização do trabalho, passou a questionar a divisão do resultado da colheita em duas partes apenas, se o agricultor do lote 10 era sozinho. $O$ agricultor do lote 10 não concordou que a divisão se fizesse em três partes, e assim instalou-se um conflito.

Buscando auxílio para que antigo trato fosse mantido, o agricultor do lote 10, primeiramente, queixou-se ao técnico agrícola do Itesp que lhe dava assistência, e este prometeu levar sua reclamação para os coordenadores do "Programa Pontal Verde". Como, em seu entendimento, não houve resposta, dirigiu-se ao escritório local do Itesp para queixarse pessoalmente. Os funcionários do escritório não sabiam que medida poderia ser tomada, e o supervisor do GGA não tomou nenhuma atitude. Quando perguntado sobre os mecanismos de interferência do "Programa" neste tipo de conflito, a resposta foi coerente com os acontecimen- 
tos: "Eles resolvem tudo individualmente. Não temos como interferir". Ao se aproximar a colheita da mandioca o agricultor do lote 10, para evitar um problema maior, concordou em dividir a produção em três partes, criando-se assim uma espécie de pacto para a colheita. Realizada a colheita, e dividida em três partes, os agricultores acertaram um encontro para definir as estratégias para o próximo plantio. Entretanto, os conflitos pela divisão da produção deixaram cicatrizes e semanas depois da colheita os agricultores ainda não haviam se encontrado. Diante disso rompia-se praticamente a parceria entre esses agricultores. Na seqüência, e aproveitando-se da maior proximidade com a área, o agricultor do lote 08 iniciou, junto com seu filho, o preparo do solo para o cultivo, não sendo sequer questionado pelo outro agricultor.

Com o fim desta parceria, a trajetória do agricultor do lote 08 foi muito ilustrativa para analisarmos os desencontros do "Programa Pontal Verde". Alguns meses depois este agricultor notou que as plantas estavam sendo atacadas por formigas e, para combatê-las, solicitou formicida ao Itesp para o devido manejo. Não foi atendido. Então comprou e utilizou formicida com recursos próprios e, como chegava a época de plantio, fez outra solicitação ao Itesp, desta vez pedindo um novo preparo da área. Igualmente não foi atendido. Assim, o agricultor, descapitalizado e desassistido, não plantou nada naquele momento. Com a estação das chuvas, como era de se esperar, o mato cresceu pujante, o que para os princípios agroecológicos do "Programa" era muito interessante. Três meses depois, este agricultor solicitou novamente ao Itesp que ajudasse a limpar a área. Contudo, novamente, recebeu resposta negativa da agência, desta vez por que esta área tornara-se uma "mata enriquecida" e, conseqüentemente, não autorizou o serviço. A partir daí, o agricultor, resignado, passou apenas a contemplar o crescimento das espécies por ele plantadas, agora em terreno enriquecido pela natureza.

Posteriormente, este agricultor recebeu uma nova área para cultivo. Contudo, mesmo acreditando no Programa, o agricultor passou a desconfiar da parceria. Ele aguardou a realização dos serviços técnicos e, quando os viu concluídos, imediatamente cultivou a nova área com feijão. Quando recebeu as mudas, o adubo e o formicida, informou o Itesp que, temendo pelo atraso no recebimento do material, efetuara o 
plantio de algumas culturas. Quando colheu o feijão, efetuou o plantio de algumas mudas e novamente trabalhou a terra, desta vez com milho. Deste modo, sucessivamente, durante a realização desta pesquisa verificamos que o agricultor estava indo para a quarta safra de milho, e não pretendia recuperar aquela área, mesmo sabendo tratar-se de uma área pública de RFL.

Diante desse curioso caso, e dessa ilegal situação, a posição do Itesp foi um tanto quanto contraditória. Por um lado alegou que se tratava de uma parceria e que "a partir do momento que ela é feita, a área torna-se deles, não legalmente, mas na prática". O supervisor do GGA informava, então, que não dispunha de ferramentas de controle e que nada podia fazer para evitar este tipo de situação. "Prevemos a menor interferência possível e com isso damos maior liberdade ao agricultor", respondia eximindo-se de sua responsabilidade pública. Contudo, quando indagado sobre os resultados ambientais do "Programa Pontal Verde", especificamente sobre a diminuição de perda de solo na região, respondeu que "o Programa está apresentando resultados acima dos esperados". E o agricultor complementaria: "na marra".

\section{Área 2}

Esta área foi considerada pelo GGA como "uma das melhores áreas" do "Programa Pontal Verde". Não sem razão, pois desde a sua cessão formou-se ali uma parceria quase desprovida de conflitos. A cooperação que se firmou entre os agricultores dos lotes 28 e 29 foi considerada exemplar também "porque ambos são de temperamento calmo, não ameaçando muito o escritório". Mesmo assim, com todas esses pontos positivos, a parceria não foi adiante. Neste caso, o problema não foi por divergências entre os agricultores, mas sim porque o agricultor do lote 28 recebeu uma outra área para cultivo, exclusivamente para o seu trabalho. É relevante fazer constar que o agricultor do lote 29 possui quatro filhos com idade entre 12 e 22 anos. Essa força de trabalho (grifo nosso) foi considerada fundamental no plantio das mudas, liberando o chefe da família para outras atividades ligadas à produção e à comercialização. Já o agricultor do lote 28 possui apenas 
um filho de 14 anos de idade que estuda na cidade e, por isso, não pode ajudar durante todo o dia. Outro ponto a ser considerado é a distância: o agricultor do lote 29 distava 200 metros da referida área, ao passo que o agricultor do lote 28 caminhava cerca de 1.300 metros até chegar ao local de trabalho.

As informações apresentadas acima são como uma justificativa de que a parceria fora interrompida apenas porque o agricultor 28 recebera outra área.. Este agricultor estava diante de uma situação desfavorável: o processo de plantio das mudas lhe tomara muito tempo e sua manutenção também. O agricultor, uma vez plantadas as mudas, compareceu na área com menos freqüência que o seu parceiro. Isso criou-lhe dificuldades, visto que o distanciamento, sobretudo quando se trata de cooperação entre vizinhos, funciona como um elemento desagregador no meio rural. Mesmo não havendo cobrança por parte do agricultor 29, durante a segunda semeadura da área, o agricultor do lote 28 não compareceu em dias considerados fundamentais para a atividade, evidenciando uma certa insatisfação com a situação. Entretanto é certo que, neste momento, o agricultor do lote 28 já esperava a liberação de uma outra área, exclusiva, bem mais próxima ao seu lote. Quando saiu a liberação da área, ele comunicou ao outro agricultor a sua decisão de suspender a parceria. Não obstante, ainda foi realizada a divisão da produção, naquela safra de feijão.

A partir daí a área ficou sob a tutela exclusiva do agricultor do lote 29. Diversas culturas foram plantadas em consórcio com as mudas: feijão, mandioca, milho e urucum. Em nossa última visita a essa área, originalmente de 2 hectares, constatamos que a mesma estava ampliada para 4 hectares. Entretanto, o consórcio de culturas estava ocorrendo somente na área recebida posteriormente, também de 2 hectares. Segundo a Coordenação do Programa, "a área original receberá agora mudas desenvolvidas para produzir na sombra... é mais um passo para fechar a área". Ou seja: a visão do GGA é a de que as árvores, após atingirem um determinado tamanho, devem ser preservadas, e o agricultor, considerado como uma ameaça, deve receber, então, uma outra área para continuar parceiro do Pontal Verde. Diante de tal fato, colocamos em dúvida o projeto do "Programa Pontal Verde" questionando se há realmente o propósito de despertar nos agricultores assentados o 
interesse pelas questões ambientais e de promover a melhoria de sua condição socioeconômica ou se pretende tê-los como ajudantes do campo (grifo nosso) para a recomposição de uma área devastada.

Podemos exemplificar as dificuldades de recomposição de uma determinada área informando sobre os acontecimentos ocorridos a partir do fim da parceria entre os referidos agricultores. Quanto ao agricultor do lote 29 , verificamos que as suas áreas evoluíram de acordo com o proposto pelo GGA. Entretanto, a nova área recebida pelo agricultor do lote 28 nos é paradigmática. Este agricultor, alguns dias depois de receber a área, as mudas e o preparo do solo, decidiu que não plantaria as mudas naquele período, alegando estar sozinho para a realização do trabalho. Contudo, naquele mesmo período, plantou milho na referida área. Colhido o milho, este agricultor comunicou ao Itesp que decidira fazer uma pequena horta para seu sustento em parte da área, e propôs ao órgão, aproveitando-se do momento, a criação de uma horta comunitária naquele local. Para tanto, ele abriria mão da concessão da área desde que o Itesp lhe concedesse algum tipo de incentivo, como sementes e insumos químicos. A resposta foi negativa, e mesmo assim este agricultor plantou $1 / 2$ hectare dessa área com produtos da oleicultura. Na primeira safra, carregou seu carro com os produtos, levou-os até a cidade e vendeu-os de porta em porta. Como a receptividade fora muito boa, resolveu investir na idéia e, atualmente, cultiva 1,5 hectares da área de RFL com uma produtiva e bem cuidada horta. Toda semana este agricultor se desloca até o município de Cuiabá paulista para comercializar sua produção, auferindo assim, um incremento à sua renda.

Sobre este caso, novamente o GGA diz ser impossível interferir. Contudo, os técnicos reconhecem a ilegalidade da situação ao admitirem que o agricultor se apropria de um bem público e, através dele, promove a ampliação da sua fonte de renda. "Bem ou mal, está muito melhor do que estava, não está? A renda dele não está melhor? Cuidar do meio ambiente também é isso..." afirmava, e ao mesmo tempo argumentava o supervisor do Programa. O agricultor sabe que essa situação é ilegal, aliás "como muitas outras" que já viveu e que ainda vive. Desta maneira, com todas estas resistências e transformações, o "Programa Pontal Verde" está rumando para o seu sexto ano. 


\section{Considerações finais}

Após a apresentação destes casos, com as evidências empíricas coletadas ao longo das pesquisas de campo, concluímos que, como não houve a participação dos agricultores na formulação do "Pontal Verde", ocorreram algumas mudanças significativas no Programa, que atenderam a demandas condizentes com os propósitos do Itesp. Esta pesquisa constatou também que o "Programa Pontal Verde" desenvolve-se mais pelo empenho de determinados funcionários do Itesp do que pelo entendimento mútuo da rede de atores sociais envolvidos no programa.

Os caminhos trilhados pelo "Pontal Verde" nos revelaram o descaso com que a questão ambiental ainda é tratada pelos órgãos governamentais que deveriam promovê-la. No caso, a parceria entre o Itesp e a Secretaria de Meio Ambiente paulista revelou-se incapaz de traduzir para a prática todas as boas intenções de alguns de seus funcionários. Pareceu-nos que a questão ambiental ainda não amadureceu na consciência dos gestores públicos. Não deixamos de concordar que, principalmente a partir da redemocratização do país, as políticas públicas para a região tomaram um significativo impulso. Entretanto, quando lembramos das ações destrutivas perpetradas contra as reservas do Pontal, percebemos que pouca coisa mudou do ponto de vista cultural. Em certa medida, os agricultores assentados participantes do "Programa Pontal Verde" não estão passando apenas de "ajudantes de campo". Reconhecemos aqui a importância de alguns funcionários do Itesp, principalmente dos membros do GGA, na condução de algumas políticas de caráter ambiental. Porém, seu poder de barganha está muito aquém das poderosas forças políticas que se camuflam pelos cantos do órgão, e que podem, de um momento para o outro, pôr a perder interessantes trabalhos de pesquisa e também ações efetivas que visam a melhoria das condições socioambientais.

Por outro lado, para o GGA, comprovou-se a necessidade deste grupo estar mais encaixado nas discussões que envolvem a racionalidade cultural. Talvez pela distância ainda existente entre as disciplinas ligadas às ciências agrárias e aquelas vinculadas às Ciências Sociais, este grupo não tem avançado na percepção da lógica 
cognitiva que envolve os agricultores. Isto tem dificultado sobremaneira o entendimento de algumas questões. Ainda mais, este grupo tem se situado no limite entre os extensionistas técnicos, os extensionistas com terceiro grau e os agricultores. Isto, por vezes, tem acirrado os ânimos nas relações entre eles, o que, em certa medida, e segundo nossa análise, poderia estar sendo, senão evitado, pelo menos minimizado.

\section{Referências}

ANTÔNIO, A. P. Movimento social e organização do espaço rural nos assentamentos populacionais dirigidos pelo estado: os exemplos da Alta Sorocabana no período 1960-1990. Tese (doutorado em Geografia) - Departamento de Geografia, Faculdade de Filosofia, Letras e Ciências Humanas, Universidade de São Paulo, São Paulo.

FUNDAÇÃO INSTITUTO DE TERRAS DE SÃO PAULO “JOSÉ GOMES DA SILVA. Pontal Verde: Plano de Recuperação Ambiental nos Assentamentos do Pontal do Paranapanema. São Paulo: Itesp. 1998. v.1.

GIDDENS, A. As conseqüências da modernidade. São Paulo: Unesp, 1998.

GUIVANT, J. Uso de agrotóxicos e os problemas de sua legitimação: um estudo de Sociologia Ambiental no município de Santo Amaro da Imperatriz. 1992. Tese (Doutorado em Sociologia) - Departamento de Sociologia, Instituto de Filosofia e Ciências Humanas, Universidade Estadual de Campinas, Campinas.

Heterogeneidade de conhecimentos no desenvolvimento rural sustentável. Cadernos de Ciência \& Tecnologia, Brasília, v.14, n.3, p.411-447, 1997.

LEITE, J. F. A ocupação do Pontal do Paranapanema. São Paulo: Hucitec, 1998.

LONG, N.; VILLAREAL, M. Exploring development interfaces: from the transfer of knowledge to the transformation of meaning. In: BOOTH, D. Rethinking social development: theory, research and pratice. London:

Longman, 1994.

REIJNTIES, C. et al. Agricultura e Sustentabilidade. In: REIJNTJES, C.; HAVEKORT, B.; WATERS-BAYER, A. Agricultura para o futuro: uma introdução à agricultura sustentável e de baixo uso de insumos externos. Rio de Janeiro: AS-PTA, 2000. 


\section{Abstract}

The Fundation Itesp has collect parts of the public lands in the Pontal do Paranapanema - SP, possibiliting the creation of the rurals settles, and transforming the situation social and economic in this region. Parts of this settles finds in intense state of ambiental devastation, with high rate anual of loss of soil, was reflected sinsibility in yours respectivs developments. Like this, in 1998, the governamental organization formuled the Pontal Verde Program, objetiving to promove the improvement of the ambiental conditions in the region of the Pontal do Paranapanema, compatibilizing with the social-economics development of the settles families. The objective of this research is make a analyses about the initial stage of the Program, valueding the negociations happeneds between the various social actors participatings. So that, will analyse the ways of to take up happeneds in the region, observing the intimate relationship existing between the private capital and the governamental politic. Also will be discussed, under the analyse hang of the theory of the structuration, the dicotomics presents in the speechs what aim to promote the sustentability relationships with the to take a decisions by the farmers. For last, we studies a case aiming to anlyse the transformations happeneds in the Santa Carmem settle, driver of the Program, between 1998-2000. Across the qualitative research will try to understand the relationships in the scope of the individualities of the participatings actors, and as this individualities relationships with the macro-structural set, contributing for the construction and analyses of the news paradigms. Analysing the process of the implemating of the Program, will search, specially, understand as certains conflicts finished to turn in strategies of resistances of the settles when the state program.

Key words: rurals settles; Pontal do Paranapanema; ambiental devastation. 